\title{
Quando o Cordel Desamarra as Cordas Vocais e Liberta o (En)canto do Peito: as Representações Sociais do Câncer de Mama na Poética de Cordelistas Brasileiros When the Cordel Literature Unties the Vocal Cords and Release the Song of the Chest: the Social Representations of Breast Cancer in the Poetics of Brazilian Cordel Authors \\ Cuando el Cordel Desata las Cuerdas Vocales y Liberta el (En)canto del Pecho: las Representaciones Sociales del Cáncer de Mama en la Poética de los Cordelistas Brasileños
}

Rildo Pereira da Silva

\section{Resumo}

Introduçáo: Diante da estimativa de 52.680 novos casos de câncer de mama para 2012-2013, observa-se a tendência de se enfatizar as açôes de prevenção no Brasil, o que requer comunicação objetiva entre especialistas e leigos. A literatura de cordel, quando veículo dessa comunicação, insere-se no contexto dos indivíduos aos quais se destinam as informaçôes, e é aqui adotada como fonte de dados. Objetivo: Identificar e analisar as representaçóes sociais do câncer de mama na narrativa de cordelistas brasileiros, estabelecendo relaçóes entre discurso do senso comum e discurso da oncologia, com vistas à melhor interação entre especialistas e leigos. Método: Estudo descritivo-qualitativo, com procedimentos metodológicos baseados em princípios e técnicas da análise do discurso, realizado entre janeiro e fevereiro de 2013. Resultados: As categorias: prevenção, adoecimento e tratamento foram desdobradas nas subcategorias: autoconsciência, sublimação pela amamentação, advertêncialexortação, mobilização social, alteração e regularidade, crença na tecnologia, fatores de risco, diagnóstico e enfrentamento, crença na ciência, benefícios sociais, acessibilidade, alteração e irregularidade, religiosidade, solidariedade, estética feminina e autoestima, eficácia científica, condição socioeconômica e críticas social e política. De 32 recortes discursivos, 7 foram agrupados na categoria prevenção; 13 na categoria adoecimento; e 12 na categoria tratamento, resultando a análise interpretativa em três sentidos principais: prevenção como prática social da responsabilidade; adoecimento como determinante da tomada de consciência; e tratamento como enfrentamento coletivo. Conclusáo: A literatura de cordel pode ser um poderoso meio de estímulo às práticas de prevenção. Entretanto, como gênero literário imagístico e fantasioso, requer cautela e prudência quanto às afirmaçóes divulgadas.

Palavras-chave: Neoplasias da Mama-prevenção e controle; Guias Informativos; Troca de Informaçóes; Saúde da Mulher; Pesquisa Qualitativa

Pedagogo. Especialista em Bioética e Ética Aplicada. Mestre em Tecnologia Educacional nas Ciências da Saúde. Doutorando em Epistemologia e História da Ciência. Pesquisador do Núcleo de Pesquisa e Estudos Qualitativos do Instituto Nacional de Câncer José de Alencar Gomes da Silva (NUPEQuali/INCA). Rio de Janeiro (RJ), Brasil. E-mail: rildo@inca.gov.br.

Enderę̧o para correspondência: Rua Marquês de Pombal, 125 - 70 andar. Centro, Rio de Janeiro (RJ), Brasil. CEP: 20230-240. 


\section{INTRODUÇÃO}

Escassas e esparsas são as iniciativas de estabelecer discussôes efetivas entre ciência e filosofia, ciência e arte, ciência e religião e ciência e senso comum, enfim, entre ciência e demais conhecimentos culturais da humanidade ${ }^{1}$. Sendo o câncer a terceira causa de morte entre os brasileiros, com estimativa para o biênio 2012-2013 de cerca de 518.510 novos casos, entre os quais, 52.680 deverão ser de câncer de mama feminina ${ }^{2}$, observa-se a louvável e crescente tendência de, no campo da Oncologia, enfatizar as açôes de prevenção como estratégia para reduzir a incidência de câncer no Brasil.

A partir da leitura compreensiva de três folhetos da literatura de cordel que tematizam a prevenção, o adoecimento e o tratamento em Oncologia, aqui entendidos como expressão do imaginário popular acerca dos saberes relativos ao câncer de mama, desenvolveu-se um estudo qualitativo acerca das representaçôes sociais contidas nos referidos textos, recorrendo-se às técnicas da análise do discurso. Em sentido amplo, tanto o objeto de estudo quanto os objetivos perseguidos referiram-se às representaçôes sociais do câncer de mama contemplados na literatura de cordel. Entretanto, em sentido estrito, o problema de pesquisa se corporificou por meio de duas perguntas: as representações sociais relativas ao câncer de mama, concebidas na literatura de cordel, resultam da acriticidade? Ou há uma ideologia que é conscientemente usada como estratégia nas relaçóes sociais?

O pressuposto assumido é o de que o discurso dos cordelistas fora historicamente produzido, tratando-se de uma linguagem arquitetada sob a perspectiva ideológica dos atores sociais, mesmo quando caracterizado pelo teor fantasioso e por algumas exacerbaçôes do real, marcas próprias do cordel.

A literatura de cordel é uma manifestação da cultura popular brasileira marcada por uma poética impregnada de significados locais e globais, repleta de metáforas acerca da condição humana, cabendo o destaque de um dos seus determinantes históricos: a palavra grafada para ser falada, ou seja, o discurso para ser manifesto em forma de histórias, de "causos", de narrativas transmitidas oralmente quando da reunião de pessoas ${ }^{3}$. Com teor imagístico e fantasioso, o cordel conta e reconta, cria e recria, interpreta e reinterpreta os fatos. Em tempos e lugares desprovidos de rádio e televisão, é o cunho noticioso do cordel que faz dele um recurso comunicacional que, pela oralidade das declamaçóes, proporciona acesso às informaçôes. Assim, os cordelistas podem influir significativamente na popularização das informaçôes e na releitura da realidade ${ }^{3}$.
Entendendo que as intencionalidades ideológicas podem estar presentes no discurso dos cordelistas, sejam nas dimensôes explícitas ou implícitas de seu corpusi, buscou-se identificar e analisar as representaçóes sociais referentes ao câncer de mama na narrativa de cordelistas brasileiros, além de estabelecer relaçôes entre os discursos do senso comum e da Oncologia, com vistas a contribuir para uma melhor interação entre especialistas e leigos, uma vez que é crescente o uso da literatura de cordel como meio de comunicação popular como uma das estratégias de promoção da saúde.

\section{MÉTODO}

Em referência à Resolução 196/96 do Conselho Nacional de Saúde, a pesquisa não envolveu seres humanos como sujeitos da investigação, o que dispensou o protocolo de submissão do projeto de pesquisa a um Comitê de Ética em Pesquisa.

A pesquisa constituiu-se em estudo descritivo-qualitativo com procedimentos metodológicos baseados nos princípios e nas técnicas de análise do discurso, realizados entre os meses de janeiro e fevereiro de 2013, no Rio de janeiro. Os procedimentos metodológicos constituíram-se dos seguintes passos: a) delimitação do objeto a ser estudado e definiçấo dos objetivos a serem perseguidos; b) seleção e leitura compreensiva do material empírico; c) identificação dos recortes de fala, indicativos de sentidos discursivos e das representaçóes sociais relevantes para o estudo; d) extraçáo das categorias e subcategorias empíricas emergidas do material empírico; e) agrupamento dos recortes discursivos por categorias e subcategorias empíricas; f) aporte de categorias teóricas complementares; g) análise e interpretação dos sentidos discursivos/ representaçóes sociais por meio do diálogo entre categorias empíricas e teóricas.

O termo representaçóes coletivas ${ }^{4}$ designa as categorias fundamentais constituídas do conhecimento produzido por meio da convivência social. Posteriormente, contribuiçôes teóricas de outros estudiosos ampliaram o conceito de representaçáo, entre as quais, destacam-se a que defende que as individualidades conviventes no âmbito do social não são apenas acumuladoras de informaçóes e não estão permanentemente submetidas aos condicionamentos ideológicos das instituiçôes sociais ${ }^{5}$; e a que argumenta que as representaçôes são socialmente elaboradas e compartilhadas, sendo a realidade comum aos indivíduos a promotora da comunicação, de modo que as representaçôes sociais são saberes práticos aplicados à interpretaçáo do contexto em suas dimensôes ideológica,

\footnotetext{
${ }^{i} \mathrm{Na}$ ciência em geral, o termo designa uma coletânea de dados. Neste artigo, o termo é usado em seu sentido estrito às ciências humanas e sociais, designando um corpo de dados usados para descrever e analisar um determinado fenômeno social.
} 
material e social ${ }^{6}$. O cerne da representaçáo coletiva, bem como da representação social, é a construçáo coletiva de um determinado saber social náo dissociada do contexto.

Qualquer discurso que utiliza o simbólico e o ideológico incorpora funções de representação social quando pratica formas de comunicação inseridas em um marco histórico e em um contexto social, fenômeno que vem ao encontro do objeto e dos objetivos deste estudo: o meio discursivo é a literatura de cordel; os marcos históricos são os dados relativos ao câncer de mama no âmbito da Oncologia; e o contexto, a condição sociocultural e econômica dos cordelistas.

A teoria das representaçôes sociais ocupa-se do engendramento entre significação, realidade e imagem do objeto social ${ }^{7}$, enquanto a análise do discurso $o^{\text {ii }}$ busca compreender a produção de sentidos atribuídos a um evento social e como os sujeitos o transformam em objeto simbólico e ideológico por meio do discurso, visto que sujeito e discurso estão amalgamados por uma relação de interdependência perpassada pela ideologia. Em outras palavras, a primeira procura apreender como se dáo as funçôes da representação social que atribuem sentidos ao que é discursado simbólica e ideologicamente; enquanto a segunda investiga como o simbolismo e a ideologia subjacentes no discurso são socialmente construídos. A interpretação visa à iluminação dos significados constituintes do texto e a compreender como os seus sentidos foram produzidos ${ }^{8}$, uma vez que a linguagem é prática social produtora de sentidos que, ao fazê-lo, atua sobre a realidade como um elemento simbólico forjado por sujeitos históricos.

\section{RESULTADOS}

As fontes dos dados empíricos foram os folhetos de cordel "Câncer de Mama - Mastectomizadas", "Entre o Peito e a Mama"10 e "Outubro Rosa contra o Câncer de Mama" ${ }^{11}$. A categorizaçáo se deu por meio da leitura impregnante dos textos selecionados, com vistas à saturação de sentidos, o que resultou na extração de três categorias empíricas: prevençâo, adoecimento e tratamento, que abarcam os atos de fala acerca dos aspectos, das açóes e dos contextos, aos quais o agente do discurso atribui sentidos relacionados às práticas preventivas, às experiências do adoecimento e às experiências do tratamento, comunicando assim as suas respectivas representaçóes sociais.

Após organização dos recortes discursivos nas referidas categorias, procedeu-se ao aprofundamento das mesmas, desdobrando-as em 18 subcategorias empíricas: autoconsciência, sublimação pela amamentação, advertêncial exortação, mobilização social, alteraçâo e regularidade, crença na tecnologia e fatores de risco, vinculadas à categoria prevenção; diagnóstico e enfrentamento, crença na ciência, direitos sociais, acessibilidade, alteração e irregularidade $e$ religiosidade, vinculadas à categoria adoecimento; $e$ solidariedade, estética feminina e autoestima, eficácia científica, condiçâo socioeconômica e críticas social e política, vinculadas à categoria tratamento. No total, procedeu-se a 32 recortes no material pesquisado, sendo 7 dessas ocorrências discursivas agrupadas na categoria prevençâo; 13 na categoria adoecimento; e 12 (doze) na categoria tratamento, distribuídas e reagrupadas nas respectivas subcategorias.

A categoria prevenção abarca as ideias, as significaçóes e os sentidos expressos ou simbólicos que remetem às práticas e às experiências relacionadas à reduçáo do risco de desenvolvimento do câncer de mama. Suas subcategorias podem ser sinteticamente descritas da seguinte forma: autoconsciência diz respeito à consciência sobre a autoavaliação preventiva e a autorresponsabilidade; sublimação pela amamentação refere-se à exaltação da mama por sua função de aleitamento como motivação da prevenção; advertêncialexortação constitui-se da mescla de avisos quanto às possibilidades de desenvolvimento da doença e de chamadas às práticas preventivas; mobilização social incorpora a exaltação às práticas de grupos sociais organizados em prol da prevenção; alteração e regularidade trata da observaçáo da regularidade das oscilaçôes cíclicas e naturais do corpo como ação de prevenção; crença na tecnologia corresponde às convicçóes populares quanto à veracidade do diagnóstico precoce por meio dos recursos tecnológicos; e fatores de risco compreende os determinantes voluntários ou involuntários que podem promover a exposição ao risco.

A categoria adoecimento comporta as ideias, as significaçôes e os sentidos expressos ou simbólicos atribuídos às experiências e aos sentimentos relativos ao adoecimento por câncer de mama, entendido náo como uma mudança abrupta de um estar saudável para um estar doente, mas como um processo que se inicia com o diagnóstico positivo que, para além da evolução natural da doença, também se desenvolve temporal, social e emocionalmente. Suas subcategorias se traduzem da seguinte maneira: diagnóstico e enfrentamento reúne os elementos discursivos que envolvem a tomada de decisão entre o diagnóstico positivo e o enfrentamento da doença; crença na ciência corporifica uma forte expectativa de cura por meio do conhecimento científico em oncologia; direitos sociais elenca as falas informativas acerca das conquistas a que fazem jus os adoecidos por câncer; acessibilidade engloba as dificuldades e as impossibilidades no acesso

\footnotetext{
ii São usuais as expressóes análise de discurso e análise do discurso, com predominância da segunda, o que determinou a adoção desta como padrão, exceto quando em citaçóes textuais conste a primeira expressão.
} 
Quadro 1. Demonstrativo da categoria prevenção, suas respectivas subcategorias, recortes discursivos e folhetos de cordel

\begin{tabular}{|c|c|c|c|}
\hline $\begin{array}{l}\text { CATEGORIA } \\
\text { EMPÍRICA }\end{array}$ & $\begin{array}{l}\text { SUBCATEGORIAS } \\
\text { EMPÍRICAS }\end{array}$ & RECORTES DE DISCURSO & FOLHETOS DE CORDEL \\
\hline \multirow{9}{*}{ PREVENÇÃO } & \multirow[t]{2}{*}{ Autoconsciência } & $\begin{array}{l}\text { Mulher com seios saudáveis } \\
\text { Nem lhe passa pela mente } \\
\text { Que câncer de mama existe } \\
\text { Atingindo muita gente } \\
\text { Pensar sempre em prevenção } \\
\text { Com autoavaliação } \\
\text { Evitar ficar doente }\end{array}$ & $\begin{array}{l}\text { CÂNCER DE MAMA } \\
\text { - MASTECTOMIZADAS }\end{array}$ \\
\hline & & $\begin{array}{l}\text { O seio desenvolve um nódulo } \\
\text { De tecido conjuntivo } \\
\text { Por isso que é necessário } \\
\text { O autoexame preventivo }\end{array}$ & $\begin{array}{l}\text { ENTRE O PEITO } \\
\text { E A MAMA }\end{array}$ \\
\hline & $\begin{array}{l}\text { Sublimação pela } \\
\text { amamentação }\end{array}$ & $\begin{array}{l}\text { As glândulas e ductos de leite } \\
\text { Eles estão embutidos } \\
\text { Nos tecidos gordurosos } \\
\text { Os quais são atribuídos } \\
\text { Levar o leite das glândulas } \\
\text { Tornar os bicos nutridos }\end{array}$ & $\begin{array}{l}\text { ENTRE O PEITO } \\
\text { E A MAMA }\end{array}$ \\
\hline & \multirow{3}{*}{$\begin{array}{l}\text { Advertência / } \\
\text { Exortação }\end{array}$} & $\begin{array}{l}\text { É também uma doença } \\
\text { Que mais mata no país, } \\
\text { Mas pode ser evitada, } \\
\text { Cortando o mal na raiz, } \\
\text { Tratando bem no começo, } \\
\text { Pra ter a vida feliz }\end{array}$ & $\begin{array}{l}\text { OUTUBRO ROSA } \\
\text { CONTRA O CÂNCER DE } \\
\text { MAMA }\end{array}$ \\
\hline & & $\begin{array}{l}\text { Se for homem fique esperto } \\
\text { Pois livre não está não } \\
\text { O câncer de mama chega } \\
\text { Sem fazer a distinção } \\
\text { Na mulher é mais frequente } \\
\text { No homem mais raramente } \\
\text { Mas atinge até machão }\end{array}$ & $\begin{array}{l}\text { CÂNCER DE MAMA } \\
\text { - MASTECTOMIZADAS }\end{array}$ \\
\hline & & $\begin{array}{l}\text { Esta cartilha não pode } \\
\text { E nem vai substituir } \\
\text { A consulta com seu médico } \\
\text { Vai apenas lhe instruir } \\
\text { Alguns esclarecimentos } \\
\text { que você deve seguir }\end{array}$ & $\begin{array}{l}\text { ENTRE O PEITO } \\
\text { E A MAMA }\end{array}$ \\
\hline & Mobilização social & $\begin{array}{l}\text { A campanha Outubro Rosa } \\
\text { Visa à conscientização } \\
\text { De toda a sociedade } \\
\text { Para dar mais atenção, } \\
\text { Alertando as mulheres, } \\
\text { Aos meios de prevenção }\end{array}$ & $\begin{array}{l}\text { OUTUBRO ROSA } \\
\text { CONTRA O CÂNCER DE } \\
\text { MAMA }\end{array}$ \\
\hline & \multirow{2}{*}{ Alteração e regularidade } & $\begin{array}{l}\text { Porque os nódulos aumentam } \\
\text { E consideradamente } \\
\text { Antes do ciclo menstrual } \\
\text { Uma tensão permanente } \\
\text { As mudanças fibrocísticas } \\
\text { São suspensas normalmente }\end{array}$ & $\begin{array}{l}\text { ENTRE O PEITO } \\
\text { E A MAMA }\end{array}$ \\
\hline & & $\begin{array}{l}\text { Uma alteração benéfica } \\
\text { De uma forma diferente, } \\
\text { É notada nos nódulos } \\
\text { Isto porque geralmente } \\
\text { Visto que incha e desincha } \\
\text { De modo subsequente }\end{array}$ & $\begin{array}{l}\text { ENTRE O PEITO } \\
\text { E A MAMA }\end{array}$ \\
\hline
\end{tabular}


Quadro 1. Continuação

\begin{tabular}{|c|c|c|c|}
\hline $\begin{array}{l}\text { CATEGORIA } \\
\text { EMPÍRICA }\end{array}$ & $\begin{array}{l}\text { SUBCATEGORIAS } \\
\text { EMPÍRICAS }\end{array}$ & RECORTES DE DISCURSO & FOLHETOS DE CORDEL \\
\hline \multirow{4}{*}{ PREVENÇÃO } & \multirow[t]{2}{*}{ Crença na tecnologia } & $\begin{array}{l}\text { O exame essencial, } \\
\text { Chamado mamografia, } \\
\text { Detecta qualquer tumor } \\
\text { Que logo se inicia, } \\
\text { Não sendo o autoexame } \\
\text { O que lhe evidencia }\end{array}$ & $\begin{array}{l}\text { OUTUBRO ROSA } \\
\text { CONTRA O CÂNCER DE } \\
\text { MAMA }\end{array}$ \\
\hline & & $\begin{array}{l}\text { A biópsia e o microscópio } \\
\text { Mostra a degeneração }\end{array}$ & $\begin{array}{l}\text { ENTRE O PEITO } \\
\text { E A MAMA }\end{array}$ \\
\hline & \multirow{2}{*}{ Fatores de risco } & $\begin{array}{l}\text { Outros fatores, sabemos, } \\
\text { São os do estilo de vida, } \\
\text { Alimentos não saudáveis, } \\
\text { Os cigarros e bebida, } \\
\text { Aumentando a incidência, } \\
\text { Dessa forma adquirida }\end{array}$ & $\begin{array}{l}\text { OUTUBRO ROSA } \\
\text { CONTRA O CÂNCER DE } \\
\text { MAMA }\end{array}$ \\
\hline & & $\begin{array}{l}\text { O aumento do risco ocorre } \\
\text { Em mulher que tem parente } \\
\text { Avó, mãe, tia ou irmã } \\
\text { O risco torna frequente } \\
\text { Tiveram câncer da mama } \\
\text { Sofreram anteriormente }\end{array}$ & $\begin{array}{l}\text { ENTRE O PEITO } \\
\text { E A MAMA }\end{array}$ \\
\hline
\end{tabular}

Fonte: Folhetos de cordel selecionados como material de pesquisa.

aos serviços de saúde no âmbito da oncologia; alteração e irregularidade trata da observação da irregularidade das oscilações cíclicas e naturais do corpo como indicativo de possível desenvolvimento da doença; e religiosidade compóe-se das referências à fé e ao divino como recursos contributivos da promoção da cura.

A categoria tratamento abrange as ideias, as significações e os sentidos expressos ou simbólicos atribuídos às experiências e aos sentimentos referentes ao tratamento do câncer de mama, entendida como o enfrentamento terapêutico da doença e seus desdobramentos econômicos, sociais e emocionais. Suas subcategorias são definidas da seguinte maneira: solidariedade constitui-se das falas discursivas que tratam da convocação social no sentido de criar uma atitude solidária para com os portadores de câncer de mama; estética feminina e autoestima reporta às falas que aludem às questóes estéticas e de autoestima originadas das intervençóes cirúrgicas no corpo da mulher, bem como as suas consequências sociais, emocionais e afetivas; eficácia científica conforma-se pelas falas de exaltação à eficácia da ciência no tratamento do câncer de mama, remetendo especialmente às estatísticas epidemiológicas; condição socioeconômica aborda as limitaçôes impostas ao tratamento pela situaçáo social e financeira de escassez, muito comum entre as mulheres brasileiras em oncoterapia do câncer de mama; e críticas social e politica conflui as falas que, de alguma forma, relacionam a negligência social e o descaso político ao agravamento do problema do câncer de mama no Brasil.

\section{DISCUSSÃO}

Três contundentes sentidos sociais ganham relevo no material empírico, cada um deles vinculados a uma das categorias e às suas subcategorias: o sentido de prevençấo como prática social da responsabilidade; o sentido de adoecimento como determinante da tomada de consciência acerca da condição de doente, entremeada por uma esperança motivadora da busca pela cura, ou seja, uma consciência esperançosa; e o sentido de tratamento como enfrentamento coletivo da doença por meio de uma espécie de mutirão social.

\section{O SENTIDO DE PREVENÇÃO COMO PRÁTICA SOCIAL DA RESPONSABILIDADE}

A eficácia da prevenção do câncer de mama está proporcionalmente relacionada à redução da exposição aos riscos, relaçáo que se dá muito mais devido aos hábitos individuais considerados saudáveis do que às açôes ou programas governamentais de abrangência coletiva. Embora náo se possa negligenciar as relaçóes de interdependência e complementaridade entre as dimensões individual e coletiva na abordagem da prevenção, o que se identifica no discurso é um sentido de prevençấo veementemente concentrado na responsabilidade individual; porém, se por um lado há uma atitude de incentivo ao estilo de vida favorável à prevenção e à detecção precoce; por outro, há uma contundente 
Quadro 2. Demonstrativo da categoria adoecimento, suas respectivas subcategorias, recortes discursivos e folhetos de cordel

\begin{tabular}{|c|c|c|c|}
\hline $\begin{array}{l}\text { CATEGORIA } \\
\text { EMPÍRICA }\end{array}$ & $\begin{array}{l}\text { SUBCATEGORIAS } \\
\text { EMPÍRICAS }\end{array}$ & RECORTES DE DISCURSO & FOLHETOS DE CORDEL \\
\hline \multirow{9}{*}{ ADOECIMENTO } & \multirow{2}{*}{$\begin{array}{l}\text { Diagnóstico e } \\
\text { enfrentamento }\end{array}$} & $\begin{array}{l}\text { E mesmo que seja um câncer } \\
\text { É partir para a ação } \\
\text { Tratamento efetuar } \\
\text { Afastar a depressão } \\
\text { Enfrentar a cirurgia } \\
\text { Também quimioterapia } \\
\text { Abraçando a solução }\end{array}$ & $\begin{array}{l}\text { CÂNCER DE MAMA } \\
\text { - MASTECTOMIZADAS }\end{array}$ \\
\hline & & $\begin{array}{l}\text { Se acaso o resultado } \\
\text { Do exame for positivo, } \\
\text { Começar o tratamento } \\
\text { Urgente, pelo motivo } \\
\text { De ser talvez um tumor } \\
\text { Do tipo mais agressivo }\end{array}$ & $\begin{array}{l}\text { OUTUBRO ROSA } \\
\text { CONTRA O CÂNCER DE } \\
\text { MAMA }\end{array}$ \\
\hline & \multirow{3}{*}{ Crença na ciência } & $\begin{array}{l}\text { As mulheres portadoras } \\
\text { Desse tipo de tumor } \\
\text { Devem procurar ajuda, } \\
\text { Sem desespero e temor, } \\
\text { Quanto mais cedo fizerem, } \\
\text { Evitarão dissabor }\end{array}$ & $\begin{array}{l}\text { OUTUBRO ROSA } \\
\text { CONTRA O CÂNCER DE } \\
\text { MAMA }\end{array}$ \\
\hline & & $\begin{array}{l}\text { Constatando alguns nódulos } \\
\text { Não se torne pessimista } \\
\text { Ás vezes o caso é benigno } \\
\text { Procure um especialista } \\
\text { Quem vai lhe esclarecer } \\
\text { É o médico mastologista }\end{array}$ & $\begin{array}{l}\text { ENTRE O PEITO } \\
\text { E A MAMA }\end{array}$ \\
\hline & & $\begin{array}{l}\text { O câncer é sempre grave, } \\
\text { Mas poderá ser tratado, } \\
\text { Com menos de um centímetro } \\
\text { Se ele for detectado, } \\
\text { A chance é noventa e cinco } \\
\text { Por cento de ser curado }\end{array}$ & $\begin{array}{l}\text { OUTUBRO ROSA } \\
\text { CONTRA O CÂNCER DE } \\
\text { MAMA }\end{array}$ \\
\hline & \multirow{3}{*}{ Direitos sociais } & $\begin{array}{l}\text { Os portadores de câncer } \\
\text { Devem manter-se informados, } \\
\text { De todos os benefícios } \\
\text { Pela lei, assegurados, } \\
\text { Durante o tratamento } \\
\text { A que estarão destinados }\end{array}$ & $\begin{array}{l}\text { OUTUBRO ROSA } \\
\text { CONTRA O CÂNCER DE } \\
\text { MAMA }\end{array}$ \\
\hline & & $\begin{array}{l}\text { Dentre outros benefícios, } \\
\text { Os pacientes cadastrados } \\
\text { No FGTS e PIS, } \\
\text { Estes podem ser sacados } \\
\text { Pra cobrir despesas médicas } \\
\text { E de impostos, isentados }\end{array}$ & $\begin{array}{l}\text { OUTUBRO ROSA } \\
\text { CONTRA O CÂNCER } \\
\text { DE MAMA }\end{array}$ \\
\hline & & $\begin{array}{l}\text { Vale transporte e remédios } \\
\text { Para amenizar a dor! } \\
\text { Psicólogo, terapeuta, } \\
\text { Nutricionista, pastor, } \\
\text { Padre e advogado, } \\
\text { Em uma ação de amor }\end{array}$ & $\begin{array}{l}\text { ENTRE O PEITO } \\
\text { E A MAMA }\end{array}$ \\
\hline & Acessibilidade & $\begin{array}{l}\text { Bem pior que o transporte } \\
\text { É fazer mamografia } \\
\text { Muitos meses pra marcar } \\
\text { Pobre sofre a agonia } \\
\text { Muitas morrem sem fazer } \\
\text { É difícil até de crer } \\
\text { O fim chega antes do dia }\end{array}$ & $\begin{array}{l}\text { CÂNCER DE MAMA } \\
\text { - MASTECTOMIZADAS }\end{array}$ \\
\hline
\end{tabular}


Quadro 2. Continuação

\begin{tabular}{|c|c|c|c|}
\hline $\begin{array}{l}\text { CATEGORIA } \\
\text { EMPÍRICA }\end{array}$ & $\begin{array}{l}\text { SUBCATEGORIAS } \\
\text { EMPÍRICAS }\end{array}$ & RECORTES DE DISCURSO & FOLHETOS DE CORDEL \\
\hline \multirow{4}{*}{ ADOECIMENTO } & \multirow{2}{*}{$\begin{array}{c}\text { Alteração e } \\
\text { irregularidade }\end{array}$} & $\begin{array}{l}\text { Mastopastia fibrocística } \\
\text { Causa forte sensação, } \\
\text { Devido aos nódulos que aumentam } \\
\text { Requer bastante atenção } \\
\text { Com o ciclo da menopausa } \\
\text { Vem a modificação }\end{array}$ & $\begin{array}{l}\text { ENTRE O PEITO } \\
\text { E A MAMA }\end{array}$ \\
\hline & & $\begin{array}{l}\text { É no ciclo menstrual } \\
\text { Que aparece a alteração } \\
\text { E só é detectado } \\
\text { Através da palpação } \\
\text { Somente o mastologista } \\
\text { Pode dar explicação }\end{array}$ & $\begin{array}{l}\text { ENTRE O PEITO } \\
\text { E A MAMA }\end{array}$ \\
\hline & \multirow[b]{2}{*}{ Religiosidade } & $\begin{array}{l}\text { O cristão pra ser feliz } \\
\text { Precisa de Jesus } \\
\text { Vencer os obstáculos } \\
\text { Com força, coragem e luz } \\
\text { Ter uma vida saudável } \\
\text { Quebrar todos os tabus }\end{array}$ & $\begin{array}{l}\text { ENTRE O PEITO } \\
\text { E A MAMA }\end{array}$ \\
\hline & & $\begin{array}{l}\text { Cada um dá o que pode } \\
\text { Um real vale um milhão } \\
\text { Quando é dado com amor } \\
\text { Jesus multiplica o pão } \\
\text { Amenizar sofrimento } \\
\text { Se torna grande acalento } \\
\text { O recanto dando a mão }\end{array}$ & $\begin{array}{l}\text { CÂNCER DE MAMA } \\
\text { - MASTECTOMIZADAS }\end{array}$ \\
\hline
\end{tabular}

Fonte: Folhetos de cordel selecionados como material de pesquisa.

Quadro 3. Demonstrativo da categoria tratamento, suas respectivas subcategorias, recortes discursivos e folhetos de cordel

\begin{tabular}{|c|c|c|c|}
\hline $\begin{array}{l}\text { CATEGORIA } \\
\text { EMPÍRICA }\end{array}$ & $\begin{array}{c}\text { SUBCATEGORIAS } \\
\text { EMPÍRICAS }\end{array}$ & RECORTES DE DISCURSO & FOLHETOS DE CORDEL \\
\hline \multirow{4}{*}{ TRATAMENTO } & \multirow{4}{*}{ Solidariedade } & $\begin{array}{l}\text { Como todos nós sabemos, } \\
\text { Ela é silenciosa, } \\
\text { Surge com poucos sintomas, } \\
\text { Cresce de forma espantosa, } \\
\text { Por isso existe a campanha } \\
\text { Chamada Outubro Rosa }\end{array}$ & $\begin{array}{l}\text { OUTUBRO ROSA } \\
\text { CONTRA O CÂNCER DE } \\
\text { MAMA }\end{array}$ \\
\hline & & $\begin{array}{l}\text { Também o Rotary Dunas } \\
\text { Sediado em Fortaleza } \\
\text { Esta causa abraçou } \\
\text { Sendo um gesto de nobreza } \\
\text { Vamos todos dar a mão }\end{array}$ & $\begin{array}{l}\text { CÂNCER DE MAMA } \\
\text { - MASTECTOMIZADAS }\end{array}$ \\
\hline & & $\begin{array}{l}\text { Se este poema tocou } \\
\text { Bem lá no teu coração } \\
\text { E queira colaborar } \\
\text { Para esta nobre missão } \\
\text { Elas vão te agradecer } \\
\text { E querer te conhecer } \\
\text { Pelo ato do irmão }\end{array}$ & $\begin{array}{l}\text { CÂNCER DE MAMA } \\
\text { - MASTECTOMIZADAS }\end{array}$ \\
\hline & & $\begin{array}{l}\text { Quem tiver câncer de mama } \\
\text { Venha pra este ambiente } \\
\text { Vamos cuidar de você } \\
\text { Muito carinhosamente } \\
\text { Mas se não tiver } \\
\text { Venha ajudar a gente }\end{array}$ & $\begin{array}{l}\text { ENTRE O PEITO } \\
\text { E A MAMA }\end{array}$ \\
\hline
\end{tabular}


Quadro 3. Continuação

\begin{tabular}{|c|c|c|c|}
\hline $\begin{array}{l}\text { CATEGORIA } \\
\text { EMPÍRICA }\end{array}$ & $\begin{array}{l}\text { SUBCATEGORIAS } \\
\text { EMPÍRICAS }\end{array}$ & RECORTES DE DISCURSO & FOLHETOS DE CORDEL \\
\hline \multirow{8}{*}{ TRATAMENTO } & \multirow{3}{*}{$\begin{array}{l}\text { Estética feminina } \\
\text { e autoestima }\end{array}$} & $\begin{array}{l}\text { A mulher que tira a mama } \\
\text { É a mastectomizada } \\
\text { Pode colocar a prótese } \\
\text { Aparência melhorada } \\
\text { Aumentando a autoestima } \\
\text { Confiante e mais pra cima } \\
\text { Ficando mais desejada }\end{array}$ & $\begin{array}{l}\text { CÂNCER DE MAMA } \\
\text { - MASTECTOMIZADAS }\end{array}$ \\
\hline & & $\begin{array}{l}\text { Fabricam algumas próteses } \\
\text { Com grande dedicação } \\
\text { Preenchendo o sutiã } \\
\text { Dentro dele acoplarão } \\
\text { Melhorando a aparência } \\
\text { Se sentem com mais decência } \\
\text { E bem menos rejeição }\end{array}$ & $\begin{array}{l}\text { CÂNCER DE MAMA } \\
\text { - MASTECTOMIZADAS }\end{array}$ \\
\hline & & $\begin{array}{l}\text { É rejeição sim senhor } \\
\text { Ao saber se questionam } \\
\text { Muitos homens tiram o time } \\
\text { As esposas abandonam } \\
\text { Não bastasse a doença } \\
\text { Inda vem indiferença } \\
\text { Muitas delas desmoronam }\end{array}$ & $\begin{array}{l}\text { CÂNCER DE MAMA } \\
\text { - MASTECTOMIZADAS }\end{array}$ \\
\hline & \multirow{2}{*}{ Eficácia científica } & $\begin{array}{l}\text { Os resultados análogos } \\
\text { De estudos internacionais } \\
\text { Em mulheres com tumores } \\
\text { Em estados iniciais } \\
\text { Noventa e oito por cento } \\
\text { Tiveram curas normais }\end{array}$ & $\begin{array}{l}\text { ENTRE O PEITO } \\
\text { E A MAMA }\end{array}$ \\
\hline & & $\begin{array}{l}\text { Lá nos Estados Unidos } \\
\text { Chegou uma conclusão } \\
\text { O índice de morte por câncer } \\
\text { Houve grande redução } \\
\text { Trinta por cento dos casos } \\
\text { Após uma operação }\end{array}$ & $\begin{array}{l}\text { ENTRE O PEITO } \\
\text { E A MAMA }\end{array}$ \\
\hline & Condição socieconômica & $\begin{array}{l}\text { A carência que sê vê } \\
\text { É de cortar coração } \\
\text { Ir à quimioterapia } \\
\text { Pra fazer aplicação } \\
\text { Não tem grana pro transporte } \\
\text { Vai a pé se chega é sorte } \\
\text { Verdadeira expiação }\end{array}$ & $\begin{array}{l}\text { CÂNCER DE MAMA } \\
\text { - MASTECTOMIZADAS }\end{array}$ \\
\hline & \multirow[t]{2}{*}{ Críticas social e política } & $\begin{array}{l}\text { Concluindo este cordel } \\
\text { Já quase o dia a raiar } \\
\text { Eu parei por um instante } \\
\text { E comecei a pensar } \\
\text { Que é feito da nação } \\
\text { Vendo tanta corrupção } \\
\text { E o pobre a definhar }\end{array}$ & $\begin{array}{l}\text { CÂNCER DE MAMA } \\
\text { - MASTECTOMIZADAS }\end{array}$ \\
\hline & & $\begin{array}{l}\text { Exigindo seus direitos } \\
\text { Nos postos e hospitais, } \\
\text { Qualquer dúvida, procurem } \\
\text { Informações atuais, } \\
\text { Cuidem bem da saúde; } \\
\text { Câncer de Mama, jamais! }\end{array}$ & $\begin{array}{l}\text { OUTUBRO ROSA } \\
\text { CONTRA O CÂNCER DE } \\
\text { MAMA }\end{array}$ \\
\hline
\end{tabular}

Fonte: Folhetos de cordel selecionados como material de pesquisa. 
exortação quanto à responsabilidade como prática de prevenção. A responsabilidade individual é vista como um compromisso com a prevenção, transcendendo o limiar tênue entre individualidade e coletividade, assumindo um teor de prática social ${ }^{12}$.

A autoconsciência é a consciência do indivíduo sobre si mesmo como ser vulnerável diante do problema do câncer de mama, o que lhe impóe o dever de praticar a autoavaliação preventiva e, quem não o faz, também deve estar consciente da autorresponsabilidade: "pensar sempre em prevenção/com autoavaliação/evitar ficar doente" . Entretanto, há que se atentar para uma possível tendência de culpar o doente por sua doença, o que acaba por, mesmo que implicitamente, denotar castigo por seus hábitos de risco. Autoconsciência e autorresponsabilidade sáo conceitos inseridos na autonomia e o indivíduo as atribui a si mesmo por força da sua própria vontade; não podem ser impostas a alguém por outrem e diferem das ideias de culpa e castigo ${ }^{13}$.

A sublimação pela amamentação usa a construção social da mama como provedora da vida tenra para argumentar em favor da prática da prevenção, visto que ela constitui-se de glândulas e dutos "os quais são atribuídos/levar o leite das glândulas/tornar os bicos nutridos"10 ${ }^{10}$ evocando assim a responsabilidade do papel social da maternidade e, consequentemente, do aleitamento.

A advertêncialexortação alterna entre os sentidos de avisos quanto à necessidade de monitoramento de um possível desenvolvimento da doença e de convocação peremptória às boas práticas de prevenção com vistas à detecção precoce, constituindo-se em um misto chamamento preventivo comum de dois gêneros, já que o câncer de mama "na mulher é mais frequente/no homem mais raramente/mas atinge até machão"?

A mobilizaçâo social aponta a importância da conformação de uma consciência coletiva acerca da prevenção, configurada nas açóes de grupos sociais e movimentos organizados, tais como: "a campanha outubro rosa/[que] visa à conscientização de toda a sociedade"11.

Alteração e regularidade é uma subcategoria que enfatiza a relação entre o conjunto das alteraçóes provocadas pela menstruaçáo e suas regularidades cíclicas, apontando a oscilação natural no funcionamento do corpo feminino como um indicador de normalidade e um sinalizador para a auto-observação preventiva, pois se trata de "uma alteração benéfica/de uma forma diferente/é notada nos nódulos/isto porque geralmente/visto que incha $\mathrm{e}$ desincha/de modo subsequente" 10 .

A crença na tecnologia integra o imaginário popular de que quanto mais sofisticado o recurso tecnológico maior a veracidade do diagnóstico, atribuindo toda precisão do exame preventivo à qualidade da tecnologia utilizada: "o exame essencial,/chamado mamografia,/detecta qualquer tumor"11. Neste caso, embora as tecnologias de diagnóstico sejam também apresentadas como incentivo às práticas de prevenção, há que se ressaltar que a tecnologia em si não garante a fidedignidade dos resultados, pois esta envolve outras variáveis que podem determinar o seu nível de qualidade $^{14}$.

A subcategoria fatores de risco conjuga os sentidos de fatores voluntários e involuntários que acabam por configurar a exposição ao risco. Observando a potencialidade da carga genética, o sujeito do discurso alerta: "o aumento do risco ocorre/em mulher que tem parente/avó, mãe, tia ou irmã./O risco torna frequente/ tiveram câncer da mama/sofreram anteriormente" ${ }^{10}$, fala da qual se pode inferir que, devido à involuntariedade do componente genético, só a vigília preventiva possibilita o diagnóstico precoce. Entretanto, o interlocutor não prescinde de ressaltar a ameaça dos componentes originados dos hábitos não saudáveis: "outros fatores, sabemos,/são os do estilo de vida"11.

\section{O SENTIDO DE ADOECIMENTO COMO DETERMINANTE DA TOMADA DE CONSCIÊNCIA}

O sentido mais contundente que emerge das falas da categoria adoecimento marca-se pelo incentivo à tomada de consciência, não só acerca da doença, mas também quanto ao seu enfrentamento. No discurso, para além de ser concebido como um mal, o adoecimento por câncer de mama também assume um significado de oportunidade de superação por meio do otimismo, da determinaçáo e das ações práticas de enfrentamento.

As falas agrupadas em diagnóstico e enfrentamento dizem respeito ao primeiro momento de reflexáo e de tomada de decisão, tudo ainda sob o efeito da dupla pressão emocional provocada pelo diagnóstico positivo e a necessidade de um imediato enfrentamento, até que se conclua que o melhor "é partir para a ação/tratamento efetuar/afastar a depressáo/enfrentar a cirurgia/também quimioterapia/abraçando a solução"?.

A crença na ciência busca legitimar, no âmbito do senso comum, a soberania do conhecimento oncológico, estimulando no doente uma expectativa de cura proporcional às dimensões do tumor de mama, pressupondo assim que, "Com menos de um centímetro/ se ele for detectado,/a chance é noventa e cinco/por cento de ser curado"11. Há que se pontuar que o tamanho do tumor não é a única variável a influenciar a eficácia da intervenção científica ${ }^{15}$.

A subcategoria direitos sociais abarca as várias concessóes legais feitas aos portadores de câncer, porém, assumindo-as muito mais como incentivos ao tratamento do que como suportes socioeconômicos ou assistencialistas ${ }^{16}$, convocando os interessados a se informarem acerca "de todos os benefícios/pela lei, assegurados,/durante o tratamento"11.

O sentido preponderante na subcategoria acessibilidade denota crítica à assincronia entre a urgência da demanda 
do usuário por serviços oncológicos e $\mathrm{o}$ atendimento tardio por parte de sistema de saúde, ou seja, embora o acesso seja preconizado na legislação como direito de todos; a acessibilidade é permeada por dificultadores que retardam o tratamento ${ }^{17}$, o que pode acontecer até quando da necessidade de uma simples mamografia, já que a "pobre sofre a agonia/muitas morrem sem fazer/é difícil até de crer/o fim chega antes do dia"?.

Alteração e irregularidade evidencia um sentido de relação entre as alteraçôes menstruais cíclicas e as irregularidades inusitadas que descaracterizam o ciclo natural, indicando que tais anormalidades sinalizam a possibilidade de desenvolvimento da doença, que "É no ciclo menstrual/que aparece a alteração/e só é detectado/ através da palpação"10.

Embora fundada sobre a fé, a religiosidade também direciona-se para o sentido de estimulação à razão, a uma decisão consciente sobre o enfrentamento e, neste caso, pode ser interpretada como um contribuição à superação das angústias do adoecimento e à promoção da cura, pois "o cristão pra ser feliz/precisa de Jesus/vencer os obstáculos/com força, coragem e luz ${ }^{10}$.

\section{O SENTIDO DE TRATAMENTO COMO ENFRENTAMENTO COLETIVO}

Se na categoria prevenção a atribuição de sentidos concentra-se na responsabilidade individual, o sentido central que emerge da categoria tratamento expressa-se pela ideia de que o enfrentamento do câncer de mama na sua fase pós-diagnóstico requer uma abordagem coletiva, resignificando o tratamento como um mutirão solidário em torno do doente ${ }^{18}$, o que no âmbito da sociedade pode ser traduzido por movimentos organizados e o engajamento de todos no enfrentamento; já, especificamente no campo da Oncologia, pode ser entendido por abordagens multi e interdisciplinares ${ }^{19}$.

A subcategoria solidariedade é um duplo chamamento à mudança de atitude tanto do doente quanto do não doente. Quanto ao doente, pode ser interpretada como um convite à transição da paralisação inicial provocada pelo diagnóstico positivo para o empreendimento do tratamento. Quanto ao não doente, pode ser entendida como uma proposta de transição da inércia da indiferença para a sensibilidade colaborativa. Em ambos os casos, a solidariedade dista da compaixáo e se aproxima de uma atitude de compromisso social: "quem tiver câncer de mama/venha pra este ambiente/vamos cuidar de vocêl muito carinhosamente/mas se não tiver/venha ajudar a gente" 10 .

Também em estética feminina e autoestima há um sentido que remete a uma estética da diferença e que comporta duas dimensóes: a da autoimagem e a da imagem social da mulher mastectomizada ${ }^{20}$. Em ambas, o afeto é o elemento que, sendo um componente essencial às relaçôes sociais, é concebido como a força motriz capaz de mobilizar a mulher e também os que com ela se relacionam, mais uma vez configurando o enfrentamento como uma ação social que implica na ideia de coletividade. Sendo assim, na dimensão da autoimagem, a mulher mastectomizada tende a se sentir com a "aparência melhorada/aumentando a autoestima/confiante e mais pra cima/ficando mais desejada"'; na dimensão da imagem social, "melhorando a aparência/se sentem com mais decência/e bem menos rejeição"?

Em eficácia cientifica, há uma aberta apologia aos resultados obtidos pela Oncologia no tratamento das adoecidas por câncer de mama, também um argumento empregado como elemento motivador do movimento de enfrentamento, visto que "em mulheres com tumores/em estados iniciais/noventa e oito por cento/tiveram curas normais" 10 .

A condiçâo socioeconômica, como integrante do sentido de enfrentamento coletivo, sintetiza os aspectos sociais e financeiros da vida prática que dificultam a efetividade do tratamento do câncer de mama ${ }^{21}$, transformando o que deveria ser esperança em angústia, quando para "ir à quimioterapia/pra fazer aplicação/não tem grana pro transporte/vai a pé se chega é sorte/verdadeira expiação"?.

$\mathrm{Se}$, de alguma forma, todas as subcategorias anteriores apontam um sentido de tratamento como enfrentamento coletivo, a categoria críticas social e política não exclui as questôes políticas e sociais envolvidas no problema do câncer de mama, assumindo mesmo um tom de conclamação à organização social e de denúncia de certa indiferença política, em especial quando indaga: "que é feito da nação/vendo tanta corrupção/e o pobre a definhar"'.

Não se pode negligenciar a circularidade exaustiva que caracteriza a análise: o movimento que vai da compreensão à interpretação e da interpretação à compreensão, além da inevitável inferência exercida pelo intérprete quando da prática compreensivista. Assim como o analista teórico extrai sentidos e interpreta o discurso social, o interlocutor do discurso - ao produzi-lo - interpreta o objeto de seu discurso, em moto-contínuo dialético que envolve a perspectiva de quem interpreta e a perspectiva do que é interpretado, a fusão de horizontes ${ }^{22}$ por meio da qual se espera gerar uma "verdade" consensuada, um acordo de sentidos.

\section{CONCLUSÃO}

Não há prática social desprovida de ideologia. A ideologia configura-se na própria prática social ao conectar pensamento-linguagem-mundo e amalgamar sujeito do discurso e sentido, processos pelos quais o sujeito se constitui e significa o mundo. Tanto ciência quanto literatura são perpassadas por uma ideologia que se manifesta como uma reinterpretação do real. Logo, não 
há não ideologia ou acriticidade na literatura de cordel, pois ao fazer literário, quando de sua gênese, já subjaz uma ideologia que resulta da interação entre contexto social, texto artístico e artista popular. Portanto, devido à inseparável relação entre prática social e ideologia, conclui-se que, ao atribuir sentidos por meio de representaçóes sociais, o cordelista o faz com intencionalidades.

Entretanto, no afã de se construir um discurso capaz de mobilizar a população leiga, é preciso cuidar para não cair no mero travestimento do discurso científico por termos mais "populares", mais "fáceis" ou mais "simples", sob o risco de deturpação ou perda de informaçóes essenciais aos objetivos das açóes de prevenção, da compreensão do adoecimento e da adesão ao tratamento. No cotejamento entre texto e contexto ou, se preferirmos, entre discurso e prática social, encontrar-se-ão diferentes sentidos atribuídos à palavra mama ou à palavra câncer, por exemplo. A relação de significância entre o termo em si e a realidade na qual é empregado pode impregnar os sentidos a ele atribuídos e que, por meio dele, são expressos.

\section{CONTRIBUIÇÃO}

$\mathrm{O}$ autor trabalhou na concepção e no planejamento da pesquisa; na obtenção, na análise e na interpretação dos dados; e na redação do artigo.

\section{Declaração de Conflito de Interesses: Nada a Declarar.}

\section{REFERÊNCIAS}

1. Silva RP, Canalli WM. Alguns feitos da ciência entre a antiguidade e a idade média: representações sociais contidas na narrativa de cordelistas brasileiros. In: Fiolhais C, Simões C, Martins D, coordenadores. Livro de actas do congresso luso-brasileiro de história das ciências. Coimbra, Portugal, 2011 Out 26-29. Coimbra: UC; 2011. p.1462-80.

2. Instituto Nacional de Câncer José Alencar Gomes da Silva. Estimativa 2012: incidência de câncer no Brasil. Rio de Janeiro: INCA; 2011. 118 p.

3. Meyer M. Autores de cordel. Literatura comentada: textos selecionados, análise-literária, biografia e atividades de compreensão de texto. São Paulo: Abril Educação; 1980. 7 p.

4. Durkheim E. As regras do método sociológico. Coleção os pensadores. São Paulo: Abril Cultural; 1983. p.373-463.

5. Moscovici S. 1981. On social representation. In: Forgas JP. Social cognition: perspectives on everyday understanding. London: Academic Press; 1981. 181 p.

6. Jodelet D. La representación social: fenómenos, concepto y teoría. In: Moscovici S. Psicologia social. Paris: Press Universitaires; 1984. p.31-61.

7. Charaudeau P, Maingueneau D. Dicionário de análise do discurso. São Paulo: Contexto; 2008. 431 p.
8. Orlandi EP. Análise de discurso: princípios e procedimentos. Campinas: Pontes; 2007. 26 p.

9. Madeira L. Câncer de mama: mastectomizadas. 2011 [acesso 2013 Jan 07]. Disponível em: http://www.levimadeira. recantodasletras.com.br.visualizar.php?idt=3342499.

10. Costa P. Entre o peito e a mama. Teresina: FUNCOR; 2011 [acesso 2013 Jan 14]. Disponível em: http:// cordeldesaia.blogspot.com.br/2011/12/visita-de-creusameira-por-uma-causa.html.

11. Meira C. Outubro rosa contra o câncer de mama. 2011 [acesso 2013 Jan 28]. Disponível em: <http:// creusameiracordel.blogspot.com.br/>

12. Andrade GN, Panza AR, Vargens OMC. As redes de apoio no enfrentamento do câncer de mama: uma abordagem compreensiva. Ciênc cuid e saúde. 2011; 10(1): 82-8.

13. Marlow L, Waller J, Wardle J. Variation in blame attributions across different cancer types. Cancer Epidemiol Biomarkers Prev. 2010; 19(7):1799-805. Epub 2010 Jun 15.

14. Batiston AP, Tamaki EM, Santos MLM, Cazola LHO. Método de detecção do câncer de mama e suas implicaçôes. Cogitare enferm. 2009; 14(1):59-64.

15. Sociedade Brasileira de Mastologia; Sociedade Brasileira de Cancerologia. Diretrizes clínicas na saúde suplementar: câncer de mama - tratamento cirúrgico. Brasília, DF: AMB/ANS; 2011. 12p.

16. Milanezzi JB, Nishijima M, Sarti FM. Do assistencialismo à consolidação do Sistema Único de Assistência Social. Informaçōes FIPE 2012; 380:7-18.

17. Rodrigues CS, Givisiez GHN. Estudo da acessibilidade ao serviço de saúde de pacientes com câncer de mama no Município de Campos dos Goytacazes. Síntese, 2011; 6(1-2): 86-99.

18. Sanchez KOL, Andrade NML, Dupas G, Costa DB. Apoio social à família do paciente com câncer: identificando caminhos e direções. Rev bras enferm 2010; 63(2): 290-9.

19. Skaba MMVF, Silva RP, Silva CHD, Andrade JD, Nunes MGS, Santos ATC, et al. Impacto da implantação e desenvolvimento do Grupo de Tumor de Mama e sua contribuição à assistência, à pesquisa e ao ensino no Instituto Nacional de Câncer José Alencar Gomes da Silva. Revista bras cancerol. 2012; 58(4): 571-80.

20. Santos DB, Vieira EM. Imagem corporal de mulheres com câncer de mama: uma revisão sistemática da literatura. Ciênc. saúde coletiva 2011; 16(5): 2511-22.

21. Montagner MI, Montagner MA. Ruptura biográfica, trajetórias e habitus: a miséria do mundo é um câncer. Tempus-Actas de Saúde Coletiva 2011; 5(2): 193-216.

22. Gadamer H. Verdade e método: traços fundamentais de uma hermenêutica filosófica. 3. ed. Rio de Janeiro: Editora Vozes; 1997. 


\section{Abstract}

Introduction: Given the estimated number of 52.680 new cases of breast cancer for 2012-2013, there is a tendency to emphasize the preventive actions in Brazil, which requires objective communication between experts and laypeople. Cordel Literature, when used as a communication vehicle inserted in the context of the individuals to whom they are intended to address the information, is adopted here as a data source. Objective: To identify and analyze the social representations of breast cancer in the narrative of Brazilian Cordel authors, establishing relations between the common sense discourse and the discourse of oncology, in order to improve the interaction between experts and laypeople. Method: This research was conducted between January and February, 2013. It is a descriptive qualitative study, with methodological procedures and techniques based on principles of Discourse Analysis. Results: The categories prevention, treatment and illness were sectioned in subcategories: self-awareness, sublimation by breastfeeding, warning / exhortation, social mobilization, change and regularity, belief in technology, risk factors, diagnostic and confrontation, belief in science, social benefits, accessibility, change and irregularity, religion, solidarity, aesthetics and female self-esteem, scientific effectiveness, socioeconomic condition social and political critics. From the 32 discursive clippings, 7 were grouped in the category prevention, 13 in illness category, and 12 in the treatment category, resulting in an interpretative analysis with three main directions: prevention as a social responsibility; illness as a determinant of awareness, treatment as a collective confrontation. Conclusion: Cordel Literature can be a powerful mean of encouraging prevention practices. However, as a literary genre and imagistic fantasy, requires caution and prudence as to statements disclosed.

Key words: Breast Neoplasms-prevention \& control; Resource Guides; Information Exchange; Women's Health; Qualitative Resource

\section{Resumen}

Introducción: Delante de la estimativa de 52.680 nuevos casos de cáncer de mama para 2012-2013, se observa una tendencia de enfatizar las acciones de prevención en Brasil, lo que requiere una comunicación objetiva entre expertos y legos. La literatura de cordel (poema popular, oral con imágenes), cuando vehículo de esa comunicación, se insiere en el contexto de los individuos a los cuales se destinan las informaciones, y es aquí adoptada como fuente de datos. Objetivo: Identificar y analizar las representaciones sociales del cáncer de mama en la narrativa de cordelistas brasileños, estableciendo relaciones entre los discursos de sentido común y discurso de la oncología, con el fin de mejorar la interacción entre expertos y legos. Método: Estudio descriptivo cualitativo con procedimientos metodológicos basados en principios y técnicas de análisis del discurso, realizado entre enero y febrero de 2013. Resultados: Las categorías prevención, enfermedad y tratamiento han sido desdobladas en las subcategorias auto-conciencia, sublimación por la lactancia, advertencialexhortación, movilización social, alteración y regularidad, creencia en la tecnología, factores de riesgo, diagnóstico y afrontamiento, creencia en la ciencia, beneficios sociales, accesibilidad, alteración y irregularidad, religiosidad, solidaridad, estética femenina y autoestima, eficacia científica, condición socioeconómica y críticas sociales y politicas. De los 32 recortes discursivos 7 han sido agrupados en la categoría Prevención, 13 en la categoría Enfermar y 12 en la categoría Tratamiento, que resulta el análisis interpretativa en tres direcciones principales: la prevención como ejecución social de la responsabilidad; enfermar como factor determinante de conciencia y tratamiento como afrontamiento colectivo. Conclusión: La literatura de cordel puede ser un poderoso medio de estimulación a las acciones de prevención. Sin embargo, como género literario del imagismo y fantasioso, que requiere precaución y prudencia en cuanto a las afirmaciones divulgadas.

Palabras clave: Neoplasias de la Mama-prevención e control; Guias de Recursos; Intercambio de Información; Salud de la Mujer; Investigación Cualitativo 